\title{
Convergence and stability of Fibonacci-Mann iteration for a monotone non-Lipschitzian mapping
}

https://doi.org/10.1515/dema-2019-0030

Received April 4, 2019; accepted July 21, 2019

\begin{abstract}
In this paper, we prove strong convergence and $\Delta$-convergence of Fibonacci-Mann iteration for a monotone non-Lipschitzian mapping (i.e. nearly asymptotically nonexpansive mapping) in partially ordered hyperbolic metric space. Moreover, we prove stability of Fibonacci-Mann iteration. Further, we construct a numerical example to illustrate results. Our results simultaneously generalize the results of Alfuraidan and Khamsi [Bull. Aust. Math. Soc., 2017, 96, 307-316] and Schu [J. Math. Anal. Appl., 1991, 58, 407-413].
\end{abstract}

Keywords: hyperbolic metric space, nearly asymptotically nonexpansive mapping, Fibonacci-Mann iteration, monotone non-Lipschitzian mapping, fixed point theorems

MSC: $47 \mathrm{H} 10,54 \mathrm{H} 25$

\section{Introduction}

Metric fixed point theory is one of the important branch of nonlinear analysis. In 1922, Banach laid the foundation of metric fixed point theory. He gave the first fixed point theorem which guarantee the existence and uniqueness of fixed point and provided a constructive method to find fixed point. After the Banach fixed point theorem several generalization came into picture. The two important extension to partially ordered metric space was given by Ran and Reuring [1] and Nieto and Rodrique López [2]. Ran and Reuring [1] applied their results to solve matrix equation while Nieto and Rodrique López [2] applied to solve differential equation. In 1965, Browder [3, 4], Göhde [5] and Kirk [6] independently gave the existence theorem for nonexpansive mapping. The existence theorem of Kirk [6] was slightly more general then the theorem of Browder and Göhde. In 2016, Dehaish and Khamsi [7] proved Browder and Göhde fixed point theorem for monotone nonexpansive mapping. Banach used Picard iteration process to approximate the fixed point for contraction mapping. When we work with slightly weaker mapping, then Picard iteration does not converge. So many iteration like Mann, Ishikawa, Krasnoseleski came into picture to sort out this problem. Schu [8] introduced modified Mann iteration based on the good behaviour of Lipschitz constant associated to the iterates of involve mappings. The modified Mann iteration scheme does not convergent for monotone mapping. Therefore, Alfuraidan and Khamsi [9] introduced Fibonacci-Mann iteration scheme and proved strong and weak convergence in partially ordered Banach space for monotone asymptotically nonexpansive mapping. It always remains a question of attraction to prove the results of linear domain into nonlinear domain. In general metric space, we don't have addition and scalar multiplication so that we can not talk about convexity, weak convergence, duals as compare to Banach space. Hence, we are unable to extend those results of Banach space

Sajan Aggarwal: Department of Mathematics, Jamia Millia Islamia, New Delhi 110025, India;

E-mail: aggarwal.maths1993@gmail.com

*Corresponding Author: Izhar Uddin: Department of Mathematics, Jamia Millia Islamia, New Delhi 110025, India;

E-mail: izharuddin1@jmi.ac.in 
which required convexity assumptions. Due to availability of a special kind of convex structure, hyperbolic spaces provide a natural platform to study the approximation of fixed point.

In this paper, we prove strong convergence and $\Delta$-convergence results of Fibonacci-Mann iteration scheme for monotone nearly asymptotically nonexpansive mapping in partially ordered hyperbolic metric space. Also, we establish the $w^{2}$-stability of Fibonacci-Mann iteration process. Further, to demonstrate the genuineness of result we construct a new example of monotone nearly asymptotically nonexpansive mapping in hyperbolic metric space.

\section{Preliminaries}

A metric space $(X, d)$ along with partial ordering $\preceq$ is denoted by $(X, d, \preceq)$. Two points $x$ and $\mathrm{y}$ in $\mathrm{X}$ are comparable whenever $x \preceq y$ or $y \preceq x$.

Definition 1. Let $(X, d, \preceq)$ be a partial order metric space. The map $T: X \rightarrow X$ is said to be monotone or order preserving if

$$
x \preceq y \Rightarrow T(x) \preceq T(y),
$$

for any $x, y \in X$.

Definition 2. [10] A mapping $T:(X, d, \preceq) \rightarrow(X, d, \preceq)$ is said to be monotone nearly Lipschitzian with respect to $a_{n}$ if for each $n \in \mathbb{N}$, there exist a constant $k_{n} \geq 0$ such that

$$
d\left(T^{n} x, T^{n} y\right) \leq k_{n}\left(d(x, y)+a_{n}\right)
$$

where $a_{n} \in[0, \infty)$ with $a_{n} \rightarrow 0$ and for every comparable element $x, y \in X$. The infimum of constants $k_{n}$ for which the last inequality hold is denoted by $\eta\left(T^{n}\right)$ and called the nearly Lipschitz constant. The monotone nearly Lipschitz mapping $T$ with sequence $\left\{\left(a_{n}, \eta\left(T^{n}\right)\right)\right\}$ is said to be monotone nearly asymptotically nonexpansive if

1. $\eta\left(T^{n}\right) \geq 1$ for all $n \in \mathbb{N}$ and

2. $\lim _{n \rightarrow \infty} \eta\left(T^{n}\right)=1$.

A point $x \in X$ is said to be fixed point of $T$ whenever $T(x)=x$ and the set of fixed point of $T$ is denoted by $F(T)$.

In 2005, Kohlenbach [11] introduced the following definition of hyperbolic metric space.

Definition 3. Let $(X, d)$ be a metric space, then $(X, d, W)$ will be the hyperbolic metric space if the function $W: X \times X \times[0,1] \rightarrow X$ satisfying

(i) $d(z, W(x, y, \alpha)) \leq(1-\alpha) d(z, x)+\alpha d(z, y)$,

(ii) $d(W(x, y, \alpha), W(x, y, \beta))=|\alpha-\beta| d(x, y)$,

(iii) $W(x, y, \alpha)=W(x, y, 1-\alpha)$,

(iv) $d(W(x, y, \alpha), W(z, w, \alpha)) \leq(1-\alpha) d(x, z)+\alpha d(y, w)$

for all $x, y, z, w \in X$ and $\alpha, \beta \in[0,1]$.

Note 1 . If only condition (i) is satisfied, then $(X, d, W)$ will be convex metric space introduced by Takahashi [12]. We say that a subset $C$ of $X$ is said to be convex if $x, y \in C$ implies that $W(x, y, \alpha) \in C$.

Linear example of hyperbolic metric space is Banach space and nonlinear examples are Hadamard manifolds, the Hilbert open unit ball equipped with the hyperbolic metric and the CAT(0) spaces.

Now we construct a example of nearly asymptotically nonexpansive mapping in hyperbolic metric space which is not in a real line. 
Example 1. [13] Let $X=\left\{\left(x_{1}, x_{2}\right) \in \mathbb{R}^{2}: x_{1}, x_{2}>0\right\}$. Define $d: X \times X \rightarrow[0, \infty)$ by

$$
d(x, y)=\left|x_{1}-y_{1}\right|+\left|x_{1} x_{2}-y_{1} y_{2}\right|
$$

for all $x=\left(x_{1}, x_{2}\right)$ and $y=\left(y_{1}, y_{2}\right)$ in $X$. Now for $\alpha \in[0,1]$, define a function $W: X \times X \times[0,1] \rightarrow X$ by

$$
W(x, y, \alpha)=\left(\alpha x_{1}+(1-\alpha) y_{1}, \frac{\alpha x_{1} x_{2}+(1-\alpha) y_{1} y_{2}}{\alpha x_{1}+(1-\alpha) y_{1}}\right) \text {. }
$$

Then we can easily verify that $(X, d, W)$ is a hyperbolic metric space.

Now, suppose that $C=[1,4] \times[1,4]$ and $T: C \rightarrow C$ be a mapping defined by

$$
T\left(x_{1}, x_{2}\right)= \begin{cases}(2,2) & \text { if } x \in[1,2) \times[1,2) \\ (4,4) & \text { if } x \in[2,4] \times[2,4]\end{cases}
$$

is a discontinuous type nearly asymptotically nonexpansive mapping with $a_{1}=14$ and $a_{n}=0$ for $n \geq 2$ $n \in \mathbb{N} . k_{n}=1$ for all $n \in \mathbb{N}$.

The generalization of definition of uniformly convex in metric space was first given by Goebel et al. [14].

Definition 4. Let $(X, d, W)$ be a hyperbolic metric space. We say that $X$ is uniformly convex if for any $a \in X$, for every $r>0$, and for each $\varepsilon>0$

$$
\delta(r, \varepsilon)=\inf \left\{1-\frac{1}{r} d\left(\frac{1}{2} x \oplus \frac{1}{2} y, a\right) ; d(x, a) \leq r, d(y, a) \leq r, d(x, y) \geq r \varepsilon\right\}>0 .
$$

In 1976, Lim [15] introduced the concept of $\Delta$-convergence in metric space.

Definition 5. Let $X$ be a complete hyperbolic metric space and $\left\{x_{n}\right\}$ be a bounded sequence in $X$. Then the type function $r\left(.,\left\{x_{n}\right\}\right): X \rightarrow[0, \infty)$ is defined by

$$
r\left(x,\left\{x_{n}\right\}\right)=\limsup _{n \rightarrow \infty} d\left(x, x_{n}\right) .
$$

The asymptotic radius $r\left(\left\{x_{n}\right\}\right)$ is given by

$$
r\left(\left\{x_{n}\right\}\right)=\inf \left\{r\left(x,\left\{x_{n}\right\}\right): \text { for } \mathrm{x} \in \mathrm{X}\right\}
$$

and the asymptotic center $A\left(\left\{x_{n}\right\}\right)$ of $\left\{x_{n}\right\}$ is defined as

$$
A\left(\left\{x_{n}\right\}\right)=\left\{x \in X: r\left(x,\left\{x_{n}\right\}\right)=r\left(\left\{x_{n}\right\}\right)\right\} .
$$

Definition 6. A bounded sequence $\left\{x_{n}\right\}$ in $X$ is said to $\Delta$-converge to $x \in X$ if $x$ is the unique asymptotic center of every subsequence $\left\{u_{n}\right\}$ of $\left\{x_{n}\right\}$. We write $x_{n} \rightarrow x\left(\left\{x_{n}\right\} \Delta\right.$-converges to $\left.x\right)$.

Lemma 1. [16] Let $C$ be a nonempty, closed and convex subset of complete uniformly convex hyperbolic metric space $X$. Then every bounded sequence $\left\{x_{n}\right\} \in X$ has a unique asymptotic center with respect to $C$.

Lemma 2. [17] Let $X$ be a uniformly convex hyperbolic space. Let $R \in[0, \infty)$ be such that $\lim \sup d\left(x_{n}, a\right) \leq R$, $\limsup _{n \rightarrow \infty} d\left(y_{n}, a\right) \leq R$ and $\lim _{n \rightarrow \infty} d\left(W\left(x_{n}, y_{n}, \alpha_{n}\right), a\right)=R$ where $\alpha_{n} \in[a, b]$, with $0<a \leq b<1$. Then we have, $\lim _{n \rightarrow \infty} d\left(x_{n}, y_{n}\right)=0$.

Definition 7. Let $C$ be a nonempty convex subset of a hyperbolic metric space $X$. Let $T: C \rightarrow C$ be a mapping. Fix $x_{0} \in C$ and $\left\{t_{n}\right\} \in[0,1]$. The Fibonacci-Mann iteration is the sequence $\left\{x_{n}\right\}$ defined by

$$
x_{n+1}=W\left(T^{f(n)} x_{n}, x_{n}, t_{n}\right),
$$

for any $n \in \mathbb{N}$, where $f(n)$ is a Fibonacci sequence defined by $f(0)=f(1)=1$ and $f(n+1)=f(n)+f(n-1)$ for $n \geq 1$. 
Lemma 3. [18] Let $\delta_{n}, \beta_{n}$ and $\gamma_{n}$ be three sequences of nonnegative numbers such that

$$
\beta_{n} \geq 1 \text { and } \delta_{n+1} \leq \beta_{n} \delta n+\gamma_{n} \text { for all } \mathrm{n} \in \mathbb{N} .
$$

If $\sum_{n=1}^{\infty}\left(\beta_{n}-1\right)<\infty$ and $\sum_{n=1}^{\infty} \gamma_{n}<\infty$, then $\lim _{n \rightarrow \infty} \delta_{n}$ exists.

Lemma 4. [9] Let $C$ be a convex and bounded nonempty subset of partially ordered hyperbolic metric space $X$. Assume that the map $T: C \rightarrow C$ is monotone. Let $x_{1} \in C$ be such that $x_{1} \preceq T\left(x_{1}\right)\left(\right.$ or $\left.T\left(x_{1}\right) \preceq x_{1}\right)$ and $t_{n} \in[0,1]$ and consider the sequence $\left\{x_{n}\right\}$ generated by (2.1). Let $p$ be fixed point of T such that $x_{1} \preceq p$ ( or $p \preceq x_{1}$ ). Then

(i) $T^{n}\left(x_{1}\right) \preceq T^{n+1}\left(x_{1}\right)$ ( or $\left.T^{n+1}\left(x_{1}\right) \preceq T^{n}\left(x_{1}\right)\right)$,

(ii) $x_{1} \preceq x_{n} \preceq p$ ( or $p \preceq x_{n} \preceq x_{1}$ ),

(iii) $T^{f(n)}\left(x_{1}\right) \preceq T^{f(n)}\left(x_{n}\right) \preceq p$ ( or $\left.p \preceq T^{f(n)}\left(x_{n}\right) \preceq T^{f(n)}\left(x_{1}\right)\right)$,

(iv) $x_{n} \preceq x_{n+1} \preceq T^{f(n)}\left(x_{n}\right)$ ( or $\left.T^{f(n)}\left(x_{n}\right) \preceq x_{n+1} \preceq x_{n}\right)$,

for any $n \in \mathbb{N}$.

(v) [19] $x_{n} \preceq p$ (or $p \preceq x_{n}$ ), provided that $\left\{x_{n}\right\} \Delta$-converges to a point $p \in C$.

\section{$3 \Delta$-convergence and strong convergence theorem}

In this section, we prove strong and $\Delta$-convegence of Fibonacci-Mann iteration for nearly asymptotically nonexpansive mapping in the setting of uniformly convex hyperbolic metric space.

Theorem 1. Let $X$ be a complete uniformly convex partially ordered hyperbolic metric space and $C$ be a nonempty, convex and closed subset of $X$ and let $T: C \rightarrow C$ be a monotone nearly asymptotically nonexpansive mapping with sequence $\left\{\left(a_{n}, \eta\left(T^{n}\right)\right)\right\}$ and $F(T) \neq \phi$ such that $\sum_{n=1}^{\infty} a_{n}<\infty$ and $\sum_{n=1}^{\infty}\left(\eta\left(T^{n}\right)-1\right)<\infty$. If sequence $\left\{x_{n}\right\}$ is defined by (2.1) with $x_{1} \preceq T x_{1}$ (or Tx $x_{1} \preceq x_{1}$ ) where $0<a \leq \alpha_{n}, \beta_{n} \leq b<1$ and $x_{1} \in C$. If $p \preceq x_{1}$ (or $x_{1} \preceq p$ ) for some $p \in F(T)$, then $\left\{x_{n}\right\} \Delta$-converges to a fixed point $x^{\star}$ of $T$.

Proof. Let $p \in F(T)$. It follows form Lemma 4 that $T^{f(n)}\left(x_{n}\right) \preceq p$.

Now,

$$
\begin{aligned}
d\left(x_{n+1}, p\right) & =d\left(W\left(T^{f(n)} x_{n}, x_{n}, t_{n}\right), p\right) \\
& \leq\left(1-t_{n}\right) d\left(T^{f(n)} x_{n}, p\right)+t_{n} d\left(x_{n}, p\right) \\
& \leq\left(1-t_{n}\right)\left[\eta\left(T^{f(n)}\right) d\left(x_{n}, p\right)+\eta\left(T^{f(n)}\right) a_{f(n)}\right]+t_{n} d\left(x_{n}, p\right) \\
& =\left(\eta\left(T^{f(n)}\right)-t_{n} \eta\left(T^{f(n)}\right)+t_{n}\right) d\left(x_{n}, p\right)+\left(1-t_{n}\right) \eta\left(T^{f(n)}\right) a_{f(n)}
\end{aligned}
$$

for $n \in \mathbb{N}$. Also,

$$
\sum_{n=1}^{\infty}\left(\eta\left(T^{f(n)}\right)-t_{n} \eta\left(T^{f(n)}\right)+t_{n}-1\right)=\sum_{n=1}^{\infty}\left(1-t_{n}\right)\left(\eta\left(T^{f(n)}\right)-1\right) \leq \sup _{1 \leq n<\infty}\left(1-t_{n}\right) \sum_{n=1}^{\infty}\left(\eta\left(T^{f(n)}\right)-1\right)<\infty
$$

and

$$
\sum_{n=1}^{\infty}\left(1-t_{n}\right) \eta\left(T^{f(n)}\right) a_{f(n)} \leq \sup _{1 \leq n<\infty}\left(1-t_{n}\right) \eta\left(T^{f(n)}\right) \sum_{n=1}^{\infty} a_{f(n)}<\infty .
$$

It follows from Lemma 3 that $\lim _{n \rightarrow \infty} d\left(x_{n}, p\right)$ exists.

Let $\lim _{n \rightarrow \infty} d\left(x_{n}, p\right)=R$. Then

$$
\limsup _{n \rightarrow \infty} d\left(T^{f(n)} x_{n}, p\right) \leq \limsup _{n \rightarrow \infty}\left[\eta\left(T^{f(n)}\right) d\left(x_{n}, p\right)+\eta\left(T^{f(n)}\right) a_{f(n)}\right]=\limsup _{n \rightarrow \infty} d\left(x_{n}, p\right)=R
$$

and

$$
\lim _{n \rightarrow \infty} d\left(x_{n+1}, p\right)=\lim _{n \rightarrow \infty} d\left(\left(1-t_{n}\right) T^{f(n)}\left(x_{n}\right) \oplus t_{n} x_{n}, p\right)=R .
$$


By using Lemma $2 \lim _{n \rightarrow \infty} d\left(T^{f(n)}\left(x_{n}\right), x_{n}\right)=0$. From Lemma 1, $\left\{x_{n}\right\}$ have unique asymptotic center. Let $A\left(x_{n}\right)=$ $x^{\star}$ and $\left\{u_{n}\right\}$ is a subsequence of $\left\{x_{n}\right\}$ such that $A\left(u_{n}\right)=u$. Now claim $x^{\star}=u$.

On contrary suppose that $x^{\star} \neq u$.

Then,

$$
\limsup _{n \rightarrow \infty} d\left(u_{n}, u\right)<\limsup _{n \rightarrow \infty} d\left(u_{n}, x^{\star}\right) \leq \limsup _{n \rightarrow \infty} d\left(x_{n}, x^{\star}\right)<\limsup _{n \rightarrow \infty} d\left(x_{n}, u\right)=\limsup _{n \rightarrow \infty} d\left(u_{n}, u\right)
$$

which is a contradiction and hence $\Delta-\lim _{n \rightarrow \infty} x_{n}=x^{\star}$.

Now, we claim that $x^{\star} \in F(T)$. Form Lemma 4, $x_{n} \preceq x^{\star}$

$$
\begin{aligned}
\limsup _{n \rightarrow \infty} d\left(T^{f(n)} x^{\star}, x_{n}\right) & \leq \limsup _{n \rightarrow \infty} d\left(T^{f(n)} x^{\star}, T^{f(n)} x_{n}\right)+\underset{n \rightarrow \infty}{\limsup } d\left(T^{f(n)} x_{n}, x_{n}\right) \\
& \leq \limsup _{n \rightarrow \infty}\left[\eta\left(T^{f(n)}\right) d\left(x^{\star}, x_{n}\right)+\eta\left(T^{f(n)}\right) a_{f(n)}\right]+\limsup _{n \rightarrow \infty} d\left(T^{f(n)} x_{n}, x_{n}\right) \\
& \leq \limsup _{n \rightarrow \infty} d\left(x^{\star}, x_{n}\right) .
\end{aligned}
$$

Since $\Delta-\lim _{n \rightarrow \infty} x_{n}=x^{\star}$

$$
\limsup _{n \rightarrow \infty} d\left(x^{\star}, x_{n}\right)<\limsup _{n \rightarrow \infty} d\left(T^{f(n)} x^{\star}, x_{n}\right) .
$$

Thus, we have $T^{f(n)} \chi^{\star}=\chi^{\star}$, which completes the proof.

Theorem 2. Let $X$ be a complete uniformly convex partially ordered hyperbolic metric space and $C$ be a nonempty, convex and closed subset of $X$ and let $T: C \rightarrow C$ be a monotone nearly asymptotically nonexpansive mapping with sequence $\left\{\left(a_{n}, \eta\left(T^{n}\right)\right)\right\}$ and $F(T) \neq \phi$ such that $\sum_{n=1}^{\infty} a_{n}<\infty$ and $\sum_{n=1}^{\infty}\left(\eta\left(T^{n}\right)-1\right)<\infty$. If sequence $\left\{x_{n}\right\}$ is defined by (2.1) with $x_{1} \preceq T x_{1}$ (or Tx $x_{1} \preceq x_{1}$ ) where $x_{1} \in C$. If $p \preceq x_{1}$ (or $x_{1} \preceq p$ ) for some $p \in F(T)$, then $\left\{x_{n}\right\}$ converges strongly to a fixed point $x^{\star}$ of $T$ if and only if $\liminf _{n \rightarrow \infty} d\left(x_{n}, F(T)\right)=0$.

Proof. It is easy to see that if $\left\{x_{n}\right\}$ converges to a point $x^{\star} \in F(T)$ then $\liminf _{n \rightarrow \infty} d\left(x_{n}, F(T)\right)=0$.

For converse part, suppose that $\liminf _{n \rightarrow \infty} d\left(x_{n}, F(T)\right)=0$. From the proof of Theorem $1, \lim _{n \rightarrow \infty} d\left(x_{n}, x^{\star}\right)$ exist. But as it is given in the hypothesis that $\liminf _{n \rightarrow \infty} d\left(x_{n}, F(T)\right)=0$, therefore $\lim _{n \rightarrow \infty} d\left(x_{n}, F(T)\right)=0$.

Thus, for a given $\epsilon>0$ there exist a $K(\epsilon) \in \mathbb{N}$ such that

$$
d\left(x_{n}, F(T)\right)<\frac{\epsilon}{2} \text { whenever } \mathrm{n}>\mathrm{K}(\epsilon) .
$$

Particularly, $\inf \left\{d\left(x_{K}, x^{\star}\right): x^{\star} \in F(T)\right\}<\frac{\varepsilon}{2}$. So there exist $x^{\star} \in F(T)$ such that $d\left(x_{K}, x^{\star}\right)<\frac{\varepsilon}{2}$. Now, for $n, m>K(\epsilon)$

$$
d\left(x_{n}, x_{m}\right) \leq d\left(x_{n}, x^{\star}\right)+d\left(x^{*}, x_{m}\right)<\epsilon .
$$

Hence $x_{n}$ is a Cauchy sequence in $C$. Since $C$ is closed subset of $X$ then $\lim _{n \rightarrow \infty} x_{n}=x^{\star} \in C$.

Theorem 3. Let $X$ be a complete uniformly convex partially ordered hyperbolic metric space and $C$ be a nonempty, convex and compact subset of $X$ and let $T: C \rightarrow C$ be a monotone nearly asymptotically nonexpansive mapping with sequence $\left\{\left(a_{n}, \eta\left(T^{n}\right)\right)\right\}$ and $F(T) \neq \phi$ such that $\sum_{n=1}^{\infty} a_{n}<\infty$ and $\sum_{n=1}^{\infty}\left(\eta\left(T^{n}\right)-1\right)<\infty$. If sequence $\left\{x_{n}\right\}$ is defined by (2.1) with $x_{1} \preceq T x_{1}$ (or Tx $x_{1} \preceq x_{1}$ ) where $0<a \leq \alpha_{n}, \beta_{n} \leq b<1$ and $x_{1} \in C$. If $p \preceq x_{1}$ (or $x_{1} \preceq p$ ) for some $p \in F(T)$, then $\left\{x_{n}\right\}$ converges strongly to a fixed point $x^{\star}$ of $T$.

Proof. From Theorem 1, we have $\lim _{n \rightarrow \infty} d\left(T^{f(n)}\left(x_{n}\right), x_{n}\right)=0$. Since $C$ is compact, so there exist a subsequence $\left\{x_{n_{k}}\right\}$ of $\left\{x_{n}\right\}$ converges strongly to $q \in C$. Therefore $\lim _{k \rightarrow \infty} d\left(x_{n_{k}}, p\right)=0$.

Now,

$$
\begin{aligned}
d\left(x_{n_{k}}, T^{f\left(n_{k}\right)} p\right) & \leq d\left(x_{n_{k}}, T^{f\left(n_{k}\right)} x_{n_{k}}\right)+d\left(T^{f\left(n_{k}\right)} x_{n_{k}}, T^{f\left(n_{k}\right)} p\right) \\
& \leq d\left(x_{n_{k}}, T^{f\left(n_{k}\right)} x_{n_{k}}\right)+\eta\left(T^{f\left(n_{k}\right)}\right) d\left(x_{n_{k}}, p\right)+\eta\left(T^{f\left(n_{k}\right)}\right) a_{f\left(n_{k}\right)} .
\end{aligned}
$$


Taking limit as $k \rightarrow \infty$, we obtain

$$
\lim _{k \rightarrow \infty} d\left(x_{n_{k}}, T^{f\left(n_{k}\right)} p\right)=0 .
$$

By uniqueness of limit we obtain $T^{f\left(n_{k}\right)} p=p$. That is $p \in F(T)$. Since $\lim _{n \rightarrow \infty} d\left(x_{n}, p\right)$ exist for every $p \in F(T)$. Hence $x_{n}$ converges strongly to $p \in F(T)$.

\section{Stability result}

A fixed point iteration is numerically stable if small perturbation (due to approximation, rounding errors etc.) during computation will produce small changes on the approximate value of the fixed point computed by methods. In 1988, Harder and Hicks [20] gave the formal definition of stability and proved some stability result for Picard, Mann and Kirk fixed point iteration procedures under various contractive conditions. Let us define the stability.

Definition 8. Let $(X, d)$ be a metric space, T be a self mapping on $X$ and $\left\{x_{n}\right\}$ be an iterative sequence produced by the mapping $T$ such that

$$
\left\{\begin{array}{l}
x_{1} \in X, \\
x_{n+1}=f\left(T, x_{n}\right),
\end{array}\right.
$$

where $x_{1}$ is an initial approximation and $f$ is a function. Assume that $\left\{x_{n}\right\}$ converges strongly to $p \in F(T)$. If for an arbitrary sequence $\left\{y_{n}\right\} \subset X$,

$$
\lim _{n \rightarrow \infty} d\left(y_{n+1}, f\left(T, y_{n}\right)\right)=0 \Rightarrow \lim _{n \rightarrow \infty} y_{n}=p,
$$

then the iterative sequence $\left\{x_{n}\right\}$ is said to be stable with respect to $T$ or simply stable.

Definition 9. [21] Let $(X, d)$ be a metric space and let $\left\{x_{n}\right\}$ and $\left\{y_{n}\right\}$ be two sequence in $X$. We say that these sequences are equivalent if

$$
\lim _{n \rightarrow \infty} d\left(x_{n}, y_{n}\right)=0
$$

The following definition of $w^{2}$-stability was given by Timis [22] in 2010.

Definition 10. Let $(X, d)$ be a metric space, $T$ be a self mapping on $X$ and $\left\{x_{n}\right\} \subset X$ be an iterative sequence given by (2.1). Suppose that $\left\{x_{n}\right\}$ converges strongly to $p \in F(T)$. If for any equivalent sequence $\left\{y_{n}\right\} \subset X$ of $\left\{x_{n}\right\}$,

$$
\lim _{n \rightarrow \infty} d\left(y_{n+1}, f\left(T, y_{n}\right)\right)=0 \Rightarrow \lim _{n \rightarrow \infty} y_{n}=p,
$$

then the iterative sequence $\left\{x_{n}\right\}$ is said to weak $w^{2}$-stable with respect to $T$.

Theorem 4. Let $X$ be a uniformly convex partially ordered hyperbolic metric space and $C$ be a nonempty, convex and closed subset of $X$ and let $T: C \rightarrow C$ be a monotone nearly asymptotically nonexpansive mapping with sequence $\left\{\left(a_{n}, \eta\left(T^{n}\right)\right)\right\}$ and $F(T) \neq \phi$ such that $\sum_{n=1}^{\infty} a_{n}<\infty$ and $\sum_{n=1}^{\infty}\left(\eta\left(T^{n}\right)-1\right)<\infty$. If sequence $\left\{x_{n}\right\}$ is defined by (2.1) with $x_{1} \preceq T x_{1}$ (or $T x_{1} \preceq x_{1}$ ) where $0<a \leq \alpha_{n}, \beta_{n} \leq b<1$ and $x_{1} \in C$. If $p \preceq x_{1}$ (or $x_{1} \preceq p$ ) for some $p \in F(T)$ and $\left\{y_{n}\right\}$ be any equivalent sequence of $\left\{x_{n}\right\}$ with $x_{n} \preceq y_{n}$ ( or $y_{n} \preceq x_{n}$ ), then the iteration process (2.1) is weak $w^{2}$-stable with respect to $T$.

Proof. Since $x_{n} \preceq y_{n}$ then by monotonicity of $T, T^{f(n)} x_{n} \leq T^{(f(n))} y_{n}$. Set

$$
\varepsilon_{n}=d\left(y_{n+1}, f\left(T, y_{n}\right)\right) \text {. }
$$

Suppose that $\varepsilon_{n} \rightarrow 0$ as $\mathrm{n} \rightarrow \infty$. Then

$$
\begin{aligned}
d\left(y_{n+1}, p\right) & \leq d\left(y_{n+1}, f\left(T, y_{n}\right)\right)+d\left(f\left(T, y_{n}\right), x_{n+1}\right)+d\left(x_{n+1}, p\right) \\
& \leq \varepsilon_{n}+t_{n}\left[\eta\left(T^{n}\right) d\left(y_{n}, x_{n}\right)+\eta\left(T^{n}\right) a_{f(n)}\right]+\left(1-t_{n}\right) d\left(y_{n}, x_{n}\right)+d\left(x_{n+1}, p\right) .
\end{aligned}
$$


By taking limit $n \rightarrow \infty$ on both side, we get

$$
\lim _{n \rightarrow \infty} d\left(y_{n+1}, p\right)=0
$$

Thus $\left\{x_{n}\right\}$ is weak $w^{2}-$ stable with respect to $T$.

\section{Example}

In this section, we construct an example of monotone nearly asymptotically nonexpansive mapping and show the convergence behaviour of Mann and Finbonacci-Mann iteration procedure.

Example 2. Let $X=\mathbb{R}, C=[0,4]$ and $T: C \rightarrow C$ be mapping defined by

$$
T x= \begin{cases}2 & \text { if } x \in[0,2) \\ 4 & \text { if } x \in[2,4]\end{cases}
$$

is discontinuous monotone nearly asymptotically nonexpansive mapping. However, $T$ is not asymptotically nonexpansive mapping. The sequence $\left\{a_{n}\right\}$ with $a_{1}=2$ is eventually constant sequence which converge to 0 , we have

$$
\|T x-T y\| \leq\|x-y\|+a_{1}
$$

and

$$
T^{n} x=4 \text { for all } \mathrm{x} \in[0,4] \text { and } \mathrm{n}>1 .
$$

It is observed that when we take $t_{n}=(0, .5]$, both Mann iteration (MI) and Fibonacci-Mann iteration (FMI) converges to fixed point and Fibonacci-Mann iteration converges faster then Mann iteration. But when we take $t_{n}=(.5,1)$, Fibonacci-Mann iteration converge for all initial value but Mann fails to converge to fixed point for some initial value. Figure 1 and Figure 2 shows the convergence behaviour of Mann iteration and Fibonacci-Mann iteration for $t_{n}=.5$ and $t_{n}=.55$ for different initial values.

Table 1: Convergence table of Mann iteration and Fibonacci-Mann iteration for $t_{n}=.5$.

\begin{tabular}{ccccccc}
\hline Iteration number & MI for $x_{1}=0$ & FMI for $x_{1}=0$ & MI for $x_{1}=1$ & FMI for $x_{1}=1$ & MI for $x_{1}=2$ & FMI for $x_{1}=2$ \\
\hline 1 & 0 & 0 & 1 & 1 & 2 & 2 \\
2 & 1 & 1 & 1.5 & 1.5 & 3 & 3 \\
3 & 1.5 & 2.5 & 1.75 & 2.75 & 3.5 & 3.5 \\
4 & 1.75 & 3.25 & 1.875 & 3.375 & 3.75 & 3.75 \\
16 & 1.9999 & 3.9998 & 2 & 3.9998 & 3.9999 & 3.9999 \\
17 & 2 & 3.9999 & 2 & 3.9999 & 4 & 4 \\
18 & 2 & 4 & 2 & 4 & 4 & 4 \\
69 & 3.9999 & 4 & 3.9999 & 4 & 4 & 4 \\
70 & 3.9999 & 4 & 4 & 4 & 4 & 4 \\
71 & 4 & 4 & 4 & 4 & 4 & 4 \\
\hline
\end{tabular}




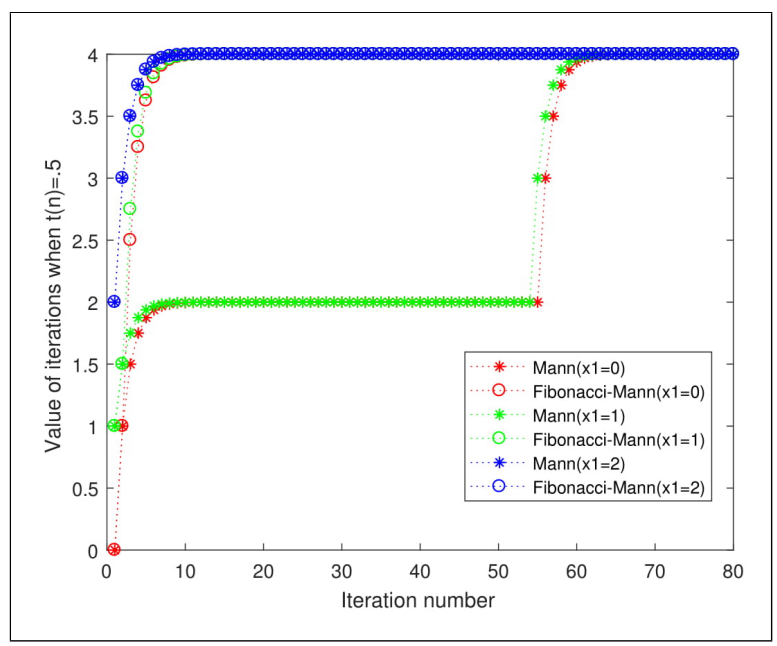

Figure 1

Table 2: Convergence table of Mann iteration and Fibonacci-Mann iteration for $t_{n}=.55$.

\begin{tabular}{ccccccc}
\hline Iteration number & MI for $x_{1}=0$ & FMI for $x_{1}=0$ & MI for $x_{1}=1$ & FMI for $x_{1}=1$ & MI for $x_{1}=2$ & FMI for $x_{1}=2$ \\
\hline 1 & 0 & 0 & 1 & 1 & 2 & 2 \\
2 & .9 & .9 & 1.45 & 1.45 & 2.9 & 2.9 \\
3 & 1.395 & 2.295 & 1.6975 & 2.5975 & 3.395 & 3.395 \\
4 & 1.6673 & 3.0622 & 1.8336 & 3.2286 & 3.6672 & 3.6672 \\
17 & 1.9999 & 3.9996 & 1.9999 & 3.9997 & 3.9999 & 3.9999 \\
18 & 1.9999 & 3.9998 & 2 & 3.9998 & 3.9999 & 3.9999 \\
19 & 2 & 3.9999 & 2 & 3.9999 & 4 & 4 \\
20 & 2 & 3.9999 & 2 & 3.9999 & 4 & 4 \\
21 & 2 & 4 & 2 & 4 & 4 & 4 \\
100 & 2 & 4 & 2 & 4 & 4 & 4 \\
10000 & 2 & 4 & 2 & 4 & 4 & 4 \\
\hline
\end{tabular}

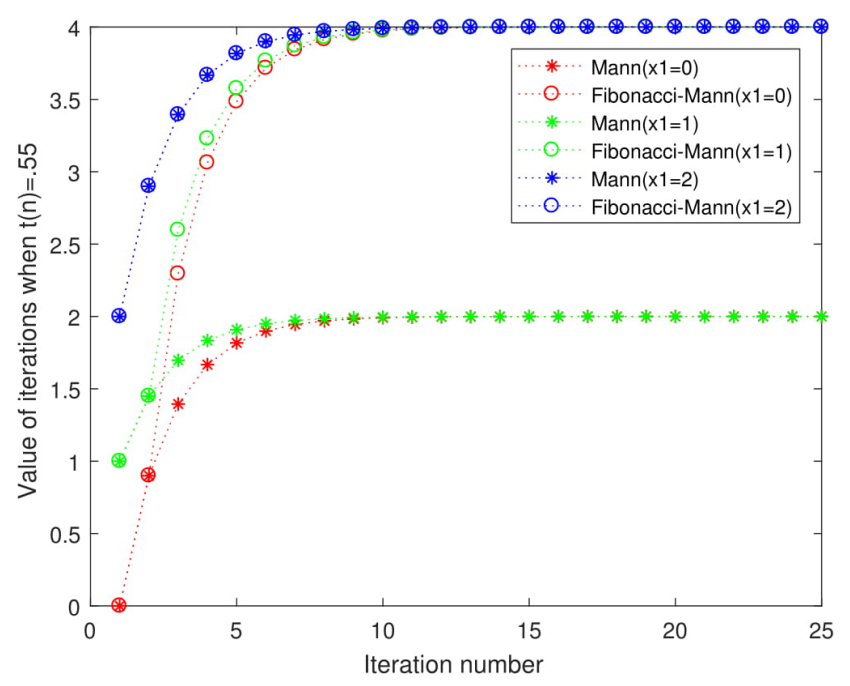

Figure 2 


\section{Acknowledgement}

Mr. Sajan Aggarwal is thankful to UGC for providing financial assistantship in form of UGC JRF, while second author (Izhar Uddin) acknowledge the support of UGC BSR Startup grant.

\section{References}

[1] Ran A. C. M., Reurings M. C. B., A fixed point theorems in partially ordered sets and some applications to matrix equations, Proc. Am. Math. Soc., 2005, 132(5), 1435-1443

[2] Nieto J. J., Rodriguez- Lopez R., Contractive mapping theorems in partially ordered sets and applications to ordinary differential equation, Order, 2005, 22(3), 223-239

[3] Browder F. E., Fixed point theorem for noncompact mappings in Hilbert space, Proc. Net. Acad. Sci. USA, 1965, 53, 1272-1276

[4] Browder F. E., Nonexpansive nonlinear operators in a Banach space, Proc. Net. Acad. Sci. USA, 1965, 54, 1041-1044

[5] Göhde D., Zum Prinzip der kontraktiven Abbildung, Math. Nachr., 1965, 30, 251-258

[6] Kirk W. A., A fixed point theorem for mappings which do not increase distances, Amer. Math. Monthly, 1965, 72, 1004-1006

[7] Dehaish B. A. B., Khamsi M. A., Browder and Göhde fixed point theorem for monotone nonexpansive mappings, Fixed Point Theory Appl., 2016, 2016:20

[8] Schu J., Iterative construction of fixed points of asymptotically nonexpansive mapping, J. Math. Anal. Appl., 1991, 58, 407413

[9] Alfuraidan M. R., Khamsi M. A., Fibonacci-Mann iteration for monotone asymptotically nonexpansive mappings, Bull. Aust. Math. Soc., 2017, 96(2), 307-316

[10] Sahu D. R., Fixed point of demicontinuous nearly Lipschitzian mappings in Banach space, Comment. Math. Uni. Carolin., 2005, 46, 653-666

[11] Kohlenbach U., Some logical metaheorems with application in functional analysis, Trans. Amer. Math. Soc., 2005, 357, 89128

[12] Takahashi W., A convexity in metric space and noonexpansive mappings, I. Kodai Math. Sem. Rep., 1970, 22, 142-149

[13] Saluja G. S., Nashine H. K., Convergence of an implicit iteration process for a finite family of asymptotically quasinonexpansive mappings in convex metric spaces, Opusc. Math., 2010, 30, 331-340

[14] Goebel K., Sekowski T., Stachura A., Uniform convexity of the hyperbolic metric and fixed points of holomorphic mappings in the Hilbert ball, Nonlinear Anal. TMA, 1980, 4, 1011-1021

[15] Lim T. C., Remarks on some fixed point theorems, Proc. Am. Math. Soc., 1976, 60, 179-182

[16] Leustean L., Nonexpansive iterations in uniformly convex W-hyperbolic spaces, In: Leizarowitz A., Mordukhovich B. S., Shafrir I., Zaslavski A., (Eds.), Nonlinear Analysis and Optimization I: Nonlinear Analysis, Contemp. Math., Am. Math. Soc., 2010, 513, 193-209

[17] Fukhar-ud-din H., Khamsi M. A., Approximating common fixed pint in hyperbolic spaces, Fixed Point Theory Appl., 2014, 2014:113

[18] Osilike M. O., Aniagbosor S. C., Weak and strong convergence theorems for fixed points of asymptotically nonexpansive mappings, Math. Cmput. Modellings, 2000, 32, 1181-1191

[19] Shukla R., Pant R., Kumam P., On the $\alpha$-nonexpansive mapping in partially ordered hyperbolic metric spaces, J. Math. Anal, 2017, 8, 1-15

[20] Harder A. M., Hicks T. L., Stability result for fixed point iteration procedures, Math. Japonica, 1988, 33, 693-706

[21] Rubbioni P., Cardinali T., A generalization of the Caristi fixed point theorem in metric space, Fixed Point Theory, 2010, 11, 3-10

[22] Timis I., On the weak stability of Picard iteration for some contractive type mappings, Annal. Uni. Craiva, Math. Comput. Sci. Series, 2010, 37, 106-114 